\title{
Analysis of Sports Injury Rate at Football Competitions Among University Students in Astrakhan City
}

\author{
Petin D.E. \\ Kozma Mini State Pedagogical University, Nizhegorod \\ Russia \\ ignat.kondrashov@yandex.ru
}

\author{
Petina E.Sh. \\ Astrakhan State Medical University \\ Astrakhan, Russia \\ elmira-petina66@rambler.ru
}

\author{
Kashirsky A.V. \\ Astrakhan State University \\ Astrakhan, Russia \\ kmn2001@mail.ru
}

\begin{abstract}
Injuries of various gravity have been identified, based on the complex analysis of the sport injury rate in academic years 2018-2019, in participants of football competitions among select teams of Astrakhan city universities. Application of mathematical analysis allowed to determine the peak time intervals of high injury level at the matches and significant correlation of the athlete qualification level to the injury rate. The data for study was derived from the official data of sport recreational early treatment center of Astrakhan city, State University policlinic, LPU 3 Injury Care Center of Astrakhan, the reports of practicing football trainers. In order to determine the injury levels of lower limbs, during the competition period, the characteristic game situations were identified, in which students were injured. The mathematical analysis is carried out with the aid of Statistica 10 package (USA) and it's application. The correlation analysis has been carried utilising Pearson correlation coefficient. The study of nature and locations of sport injuries in football playing students revealed that the injury rate dynamics during the competition period keeps the increase of the knee and ankle joints damages. Based on the carried out research, a conclusion can be made that the current upward trend in the sport injuries points at the insufficient level of the football select teams athlete qualification.
\end{abstract} period.

Keywords—student sports; football; sport injuries; competition

\section{INTRODUCTION}

In many cases, the cause of sports injuries is inadequate physical load, complex coordinate actions. It exceed the qualification of an athlete and the tasks that he is able to perform [2.6]. The sports injuries, in games, including football, relate to the sporting discipline, game position of an athlete $[1,3,5,12,14]$. Many specialists $[7,8,10,11]$ relate the character and gravity of the injuries with the anthropometric characteristics of the athlete. Special meaning in prevention of sports injuries is attributed by some researchers $[4,9,11,4,15]$ to the level of the muscular-ligamentous apparatus functional training. In this regard, this research of sport injury rate is carried out during the contest period, in the select football teams of Astrakhan city universities in academic years 20182019.

\section{RESEARCH METHODOLOGY}

The research is carried out based on the official data of Astrakhan city health-recreational institutions, related to firstvisits of student footballers, who were taking part in the football competitions among the city universities. The total number of the competition participants in 2018-2019 accounted to 220 of male students. The number of medical visits accounted to 19 cases, 23 more cases were recorded at the competition locations, in the $\log$ of the competition medical support team. The mathematical analysis is carried out with the aid of Statistica 10 (USA) package and it's application. The correlation analysis is carried utilising Pearson correlation coefficient.

\section{RESULTS}

As a result of the research, it is revealed, that the high level of sports injuries occur at the end of the competition period $(\mathrm{r}=0.571 ; \mathrm{p}<0.05)$; within the matches, the highest rate of injuries was reordered during the first 12 minutes and last 10 minutes of the game time $(\mathrm{r}=0.481 ; \mathrm{p}<0.05)$. A high level of injuries was found in the athletes of lower athlete qualification and it decreased exponentially towards the athletes of high athletic titles. Maximum level of sport injuries was observed in overweight students. It's necessary to underline that injuries of this group are characterised by special gravity: bone fracture, meniscal tear $(\mathrm{r}=0.701, \mathrm{p}<0.05)$. By the character, the injuries are distributed as follows: light injuries - over 50\%; ligament strain, ligament tear, capsule-ligament apparatus overstrain $-33 \%$, followed by bone fractures $-16 \%$; vertebral injury accounted to just 1 case. 
While studying the injuries of shoulder girdle and shoulder, the majority of injuries was the fracture of the radial bone lower end as a result of fall $-12,5 \%$; lower limb injuries were localised at the knee joints $-38,7 \%$ and ankle joints and the foot $-30,3 \%$. Lower limb injures, as a rule, were resulting from collision of players, blocking an opponent, interception of the ball at a high running speed, ball hit, falls. Distribution of players' injuries with regard to their game position has revealed that most of the injuries occurred in the attacking players $-43.8 \%$ and the midfield players $-27.5 \%$. With students playing in the defence $17.7 \%$ of injuries were found, and goalkeepers accounted for $10 \%$.

TABLE I. STRUCTURE OF INJURY RATES BY THE PARTS OF THE BODY

\begin{tabular}{|l|c|c|}
\hline & Injured part & Ratio, $\%$ \\
\hline $\mathbf{1}$ & Elbow and Forearm & 12.5 \\
\hline $\mathbf{2}$ & Knee joint & 38.7 \\
\hline $\mathbf{3}$ & Ankle joint & 30.3 \\
\hline $\mathbf{4}$ & Vertebral area & 4.2 \\
\hline $\mathbf{5}$ & Shin & 15.5 \\
\hline
\end{tabular}

\section{IV.CONCLUSION}

The result of the research makes it possible to conclude that the sport injuries in student footballers point at the insufficient athletic qualification of the players. A considerable role in sport injuries, in our opinion, is played by the competition participant selection system, based on general and special physical preparedness. It was possible to identify the risk group of students, based on their anthropometric data, absence of specialised sport outfit and experience in competitions.

In this regard, the correlations revealed in course of this research may be used as the premises for optimization of student footballers teaching and training process preparation, more thorough selection of the competition participants and for awareness-raising activity of the trainer and teacher staff on sport injury prevention. It should be noted that students having a high enough technical preparedness were injured the less during the competitions, and usage of the special outfitsemi-stiff sleeves, fixing the ankle joint, considerably allowed to avoid damages to this location. Additionally, shin guards and semi-stiff knee sleeves also lowered the rate of contact injuries.

\section{References}

[1] Dorontsev, A.V., Kozlyatnikov, O.A. Characteristics and structure of disease rates of various groups of school children of Astrakhan oblast. Scientific notes of University named after P.F. Lesgaft. 2014, vol.11(117), pp. 46-49.

[2] Dorontsev A.V. , Gorst V.R., Medvedeva A.S. Determination of risk factors of neurological pathology development in structural elements of the vertebral spine, in persons doing power sports. Scientific notes of University named after P.F. Lesgaft. 2017, vol. 8(150), pp. 25-29.

[3] Morozova O.V., Zinchuk N.A., Dorontsev A.V., Kashirsky A.V. Correlation of sport injuries structure and athlete qualification in rhythmic-sportive gymnastics. Russian Journal of Physical Education and Sport. 2019, vol. 14(1), pp. 89-93. DOI: 10.14526/2070-47982019-14-1-89-93

[4] Svetlichkina A.A. Dorontsev A.V. Differential diagnostics criteria of cardiovascular system in persons doing rhythmic-sportive gymnastics. Scientific notes of University named after P.F. Lesgaft. 2017, vol. 1(143), pp. 181-184.

[5] Svetlichkina A.A. Dorontsev A.V. Phenomenon of shortened PQ interval as a risk factor in physical culture and sports. Scientific notes of University named after P.F. Lesgaft., 2016, vol. 9 (139), pp. 175181 .

[6] Chichova M.A., Svetlichkina A.A. Adaptation capabilities of cardiovascular system to physical loads in persons with limited audial capabilities. Astrakhan medical journal. 2016, vol. 4, pp. 64-71.

[7] Chichkova M.A., Svetlichkina A.A., Dorontsev A.V. Evaluation of adaptive kinds of sports practicing effect on the reserve indicators of cardiovascular system in patients with neuro-sensory partial hearing of I-II degree. Human. Sport. Medicine. 2018, vol. 8, 4, pp. 117-122.

[8] Claessens, M, Claessens, C., Claessens, P. et al. Importance of determining the percentage body fat in endurance- trained athletes. Indian Heart J. 2000, vol. 52, pp. 307-314.

[9] Garthe, Ina, Raastad Truls, Sundgot-Borgen Jorunn. Effect of Weight Loss on Body Composition and Performance in Elite Athletes. Human Kinetics Journals. 2011, vol. 21(5), pp. 426-435

[10] Kazemi. Mohsen, Waalen Judith, Morgan Crostopher, White Anthony R. A Profile Of Olympic Taekwondo Competitors. J Sports Sci Med. 2006. -Jul; 5 (CSSI). - P. 114-121.

[11] Kenneth, J.E., Stacey, B.J., Chertow, G.M. Bioelectrical impedance methods in clinical research: a follow- up to the NIH technology assessment conference. Nutrition. 1999, vol. 15, pp. 874-880.

[12] Kotler, D.P., Burastero, S., Wang, J., Pierson, R.N. Prediction of body cell mass, fat-free mass, and total body water with bioelectrical impedance analysis: effects of race, sex, and disease. I Am J Clin Nutr. 1996, vol. 64, pp. 489-497.

[13] Zinchuk N.A., Yermolina N.V., Dorontsev A.V., Svetlichkina A.A Study of therapeutic physical exercise impact on the functional status of elderly women. Advances in Gerontology. 2019, vol. 9(1), pp. 98-100.

[14] Ozcakar, L., Cetin, A., Kunduracyolu, B. et al. Comparative body fat assessment in elite footballers. British Journal of Sports Medicine. 2003, vol. 37, pp. 278-279.

[15] Salci, Yasar. The metabolic demands and ability to sustain work outputs during kickboxing competitions. International Journal of Performance Analysis in Sport. 2015, vol. 15(1), pp. 39-52.

[16] Aleksandr S. Kuznetsov. Russian Professor's meeting. Russian Journal of Physical Education and Sport. 2019, vol. 14(1), pp. 17-22. DOI: 10.14526/2070-4798-2019-14-1-18-24. 